\title{
ACOUSTO-ELECTRIC STUDY OF INTERFACE TRAPPING DEFECTS IN GaAs EPITAXIAL STRUCTURES
}

\author{
I. V. Ostrovskii ${ }^{\dagger}$, S. V. Saiko ${ }^{\dagger}$, O. Ya. Olikh ${ }^{\dagger}$, H. G. Walther ${ }^{\ddagger}$ \\ ${ }^{\dagger}$ Kiev Shevchenko University, Physics Faculty, Kiev, UA-252022, Ukraine \\ $\ddagger$ Friedrich Schiller University, Institute for Optics and Quantum Electronics, 07743 Jena, Germany
}

(Received July 17, 1997)

\begin{abstract}
A new acousto-electrical method making use of transient transverse acousto-electric voltage (TAV) to study solid state structures is reported. This voltage arises after a surface acoustic wave (SAW) generating the signal is switched off. Related measurements consist in detecting the shape of transient voltage and its spectral and temperature dependence. Both theory and experiment show that this method is an effective tool to characterize trapping centers in the bulk as well as at surfaces or interfaces of epitaxial semiconductor structures.
\end{abstract}

Key words: acousto-electric, trapping center, epitaxial structure.

PACS number(s): 78.70.-g

\section{INTRODUCTION}

Different methods are known to study crystal defects and deep levels in semiconductors in solid state physics. Most of them, including modern Scanning Tunneling Microscopy techniques, allow to characterize surface defects. At the same time multilayer and epitaxial semiconductor structures are strongly influenced by defects [1-3] which can be located at the interfaces between epilayers and substrate. Up to now no appropriate experimental methods exist to characterize these interface defects. Recently some publications reported the transient acousto-electric effect in semiconductors with defects [46]. Transient transverse acousto-electric voltage (TAV) generated in semiconductors has already been used in the past $[7,8]$, but this using has not been aimed to interface defect characterization and has not included corresponding acousto-optical measurements.

If the TAV method is applied some difficulties of interpretation of the experimental results have to be surmounted. The point is that the TAV amplitude strongly depends on several parameters, among them the influence of piezoelectric field strength $E_{v}$ on local centers has to be mentioned. To avoid these difficulties we propose to measure the transient TAV signal just after the excitation pulse has to be switched off.

\section{THEORY}

\section{A. MECHANISMS OF THE TAV ORIGIN}

TAV is one of the manifestations of ultrasonically activated redistribution of the electrical charges in semiconductors. It is generated across layered systems consisting of piezoelectric and semiconducting materials due to a piezoactive surface acoustic wave (SAW) propagating along the piezoelectric. The SAW piezoelectric field penetrates inside the semiconductor causing charge carriers redistribution in the near surface region.
Two main mechanisms of generating the TAV effect exist in semiconductors. The first one, the so-called "concentration-effect" is due to the variable component of sample conductivity $\sigma_{v}$ [9]. It is a result of electron concentration redistribution under the action of the variable piezoelectric field $E_{v}$ of SAW. Hence, the direct component of the acousto-electric current is defined by:

$$
j_{0}={\overline{\left(\sigma_{v} E_{v}\right)}}^{T_{s}}
$$

where the averaging is carried out on the acoustic wave period $T_{s}$. The relaxation time of this TAV signal component is defined by the Maxwell's relaxation time $\tau_{m}$ of free charge carriers $\left(\tau_{m}=\epsilon \epsilon_{0} / \sigma_{0}\right)$. Usually $\tau_{m}$ is much less than the period length of SAW. Therefore one can suppose that the relaxation time of the "concentration" TAV is equals to zero.

The second mechanism of the TAV generation is connected with semiconductor defects. The presence of the high-frequency SAW electrical field in the near surface region results in increasing the free charge carriers concentration. This, in turn, causes an increasing of the electrical charge captured on deep trapping levels, which are located either at interface or surface. As a result a direct electrical field perpendicularly to the sample surface is occurring. The amplitude of this "trap" TAV component is proportional to the excess concentration of the charge captured on trap levels [10].

Let us assume that the concentration of this charge is $\Delta n_{t}(t)$. For the simplest case of only one type of surface defects existing the transient TAV the signal can be written as

$$
V_{a e}(t)=C_{a e} \Delta n_{t}(t)
$$

where the coefficient $C_{a e}$ depends on the sample parameters.

The voltage $V_{a e}(t)$ is connected to the relaxation of the electrical nonequilibrum charge trapped by surface 
defects. As far as the relaxation time does not depend on the particular mechanism of excitation of the electronic subsystem, it is possible to use a standard theoretical approach. The relaxation time $\tau$ is a function of trap level parameters. In the following we will consider an $n$-type semiconductor. Then it holds

$$
\tau=\frac{1}{N_{c} V_{T} S_{n}} e^{E_{t} / k T}
$$

where $N_{c}$ is the density of states of the conductivity band, $V_{T}$ is a thermal velocity of free electrons, $k$ is Boltzmann's constant, $T$ is temperature, $E_{t}$ is an energy depth of the electronic trap level counted from the edge of conductivity band and $S_{n}$ is an effective cross section of electron capture by trap centers.

Usually different types of trap levels exist. In this case the excess concentration $\Delta n_{t i}$ of charge carriers captured by the $i$-type surface traps, can be written as:

$$
\frac{d \Delta n_{t i}}{d t}=-\frac{\Delta n_{t i}}{\tau_{i}}+F_{i}(t)
$$

where $\tau_{i}$ represents the characteristic relaxation time of the $i$-type level, $F_{i}(t)$ is an external force, which initiates the capturing by surface traps. The physical nature of the said force is connected with the piezoelectric field of SAW.

If the ultrasonic wave amplitude is modulated by rectangular pulses the external force $F(t)$ has the form

$$
F(t)=\left\{\begin{array}{cc}
\text { const }, & 0<t<T_{p} \\
0, & T_{p}<t
\end{array}\right.
$$

where $T_{p}$ is the pulse duration. The radio frequency impulses and the corresponding TAV pulse are presented on fig. 1. The TAV pulse shows a monotonous increase ("AB") and a monotonous decrease ("BC"). This shape of the TAV signal is typical for the trap component. The measurement of the shape of the transient TAV signal is made along "BC" in fig. 1. Note that in this case the external force vanishes $(F(t)=0)$ during our measurements. In this case the solution of equ. 4 is a decreasing exponential curve with the relaxation time $\tau_{i}$. For different trap levels in the sample the TAV signal can be expressed by a sum

$$
V_{a e}(t)=V_{C}+\sum_{i=1}^{N} V_{i} e^{-t / \tau_{i}}
$$

where the times $\tau_{i}$ correspond to various $i$-levels. The summation has to be carried out over all existing traps in the near surface region. The coefficients $V_{i}$ are proportional to the concentrations of the various trap types. The first term in equ. 6 presents the contribution of "very slow" levels in TAV. Such levels can exist in the
$A_{2} B_{6}$-compounds or in MIS-structures with the relaxation times $\tau$ of about some hours while modern $A_{3} B_{5}$ epilayer structures do not have such slow levels. The signs of $V_{C}$ and $V_{i}$ are opposite for the electron and hole capture centers.

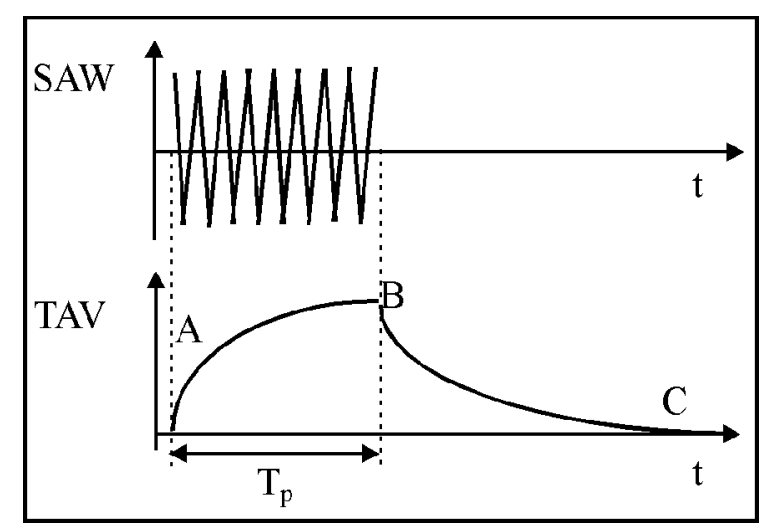

Fig. 1. Time dependence of input $r f$-voltage $V$ exciting SAW and resulting TAV signal.

Thus, it is possible to determine the relaxation time $\tau$ by measuring the TAV signal. The transient TAV relaxation time $\tau$ is determined by the rate of thermal emission and trapping of charge carriers on the surface levels. In turn, the rate of reaching the thermodynamic balance between capture centers and conduction zones in a semiconductor structure depends on characteristic parameters of these centers, such as energy depth $E_{t}$ and effective cross section $S_{n}$. The calculation of $S_{n}$ by means of equ. 3 is successful only if the energy levels $E_{t i}$ is known. For this reason additional information about $E_{t i}$ and relaxation time $\tau_{i}$ is needed. It can be obtained by measuring the optical spectra of TAV signals or the thermal dependence of the TAV signal.

\section{B. ANALYSIS OF TAV SPECTRAL DEPENDENCIES}

The illumination of a semiconductor surface changes the distribution of free and captured charge carriers. Now we consider the influence of monochromatic illumination on various components of the TAV signal. For singly charged electron traps the process of electron capturing follows the equation

$$
\frac{d n_{t}}{d t}=C_{n} n_{s}\left(N_{t}-n_{t}\right)-\beta_{n} n_{s 0} n_{t}
$$

where $N_{t}$ is the concentration of the surface trap levels, $n_{t}$ is the concentration of captured electrons; $n_{s}$ is the concentration of the free charge carriers near the semiconductor surface and $C_{n}$ and $\beta_{n}$ are the probabilities 
for capturing and releasing charge carriers. The concentrations $n_{t}$ and $n_{s}$ deviate from their equilibrium values $n_{t 0}$ and $n_{s 0}$ under the influence of ultrasonic waves:

$$
n_{t}=n_{t 0}+\Delta n_{t}, \quad n_{s}=n_{s 0}+\Delta n_{s} .
$$

The condition of the thermodynamic balance in the absence of the acoustic wave is

$$
C_{n} n_{s 0}\left(N_{t}-n_{t 0}\right)-\beta_{n} n_{s 0} n_{t 0}=0
$$

This equation provides the connection between the coefficients $C_{n}$ and $\beta_{n}$. For the non-degenerate semiconductor we obtain:

$$
\beta_{n}=C_{n} \exp \left(\left(E_{t}-F_{s 0}\right) / k T\right)
$$

where $F_{s 0}$ is the Fermi level at the surface. By substituting equs. 8 and 10 into equ. 7 , we obtain:

$$
\begin{aligned}
& \frac{d \Delta n_{t}(\lambda)}{d t}=C_{n}\left[\left(N_{t}-n_{t 0}(\lambda)\right) \Delta n_{s}\right. \\
& \left.-\left(n_{s 0}(\lambda)+\Delta n_{s 0}(\lambda)+N_{c} e^{-E_{t} / k T}\right) \Delta n_{t}(\lambda)\right] .
\end{aligned}
$$

Note, that $\Delta n_{t}$ and $\Delta n_{s}$ are averaged over the acoustic wave period. The acousto-electrical voltage component, which is connected to trapped charge, is proportional to the excess charge on the said traps $\left(V_{a e} \sim \Delta n_{t}\right)$. Performing the measurement of the TAV signal and its shape under quasi-equilibrium conditions, it means:

$$
\frac{d \Delta n_{t}}{d t}=0
$$

Then, from equ. 11 we receive the following expression for the trap TAV component:

$$
\begin{aligned}
V_{a e} & \sim \Delta n_{t}(\lambda)=\left(N_{t}-n_{t 0}(\lambda)\right) \\
& \times \frac{\Delta n_{s}(\lambda)}{\left(n_{s 0}(\lambda)+\Delta n_{s 0}(\lambda)+N_{c} e^{-E_{t} / k T}\right)} .
\end{aligned}
$$

The values $n_{t 0}, \Delta n_{s}$ and $\Delta n_{s 0}$ depend on sample illumination. However, if the photon energy $h \nu$ does not exceed the band gap energy $E_{G}$ and direct electronic excitation from the valence band to conduction band does not occur, the changes of concentrations $n_{s 0}$ and $\Delta n_{s 0}$ are rather small. In this situation the TAV spectra is mainly determined by the first co-multiplier $\left(N_{t}-n_{t 0}(\lambda)\right)$ in equ. 13. At sample illumination with light photon energies exceede the value determined by equ. 14 :

$$
E_{t}=E_{G}-h \nu
$$

the charge carriers transferring from the valence band to capture centers result in the growth of $n_{t 0}$. Then the difference $\left(N_{t}-n_{t 0}(\lambda)\right)$ in equ. 13 decreases, and a minimum should be observed in the TAV spectrum. If several types of trap levels take part in the TAV signal formation, then several corresponding minima should be observed in the optical TAV spectrum.

\section{ANALYSIS OF THE RELAXATION TIME TEMPERATURE DEPENDENCE}

The value of an energy position of the deep trap levels $E_{t}$ can also be obtained from the temperature dependence of the relaxation TAV time $\tau$. This dependence can be obtained from equ. 3 . The temperature dependence of $N_{c}$ and $V_{T}$ for the nondegenerate semiconductor is wellknown: $N_{c} \sim T^{3 / 2}, V_{T} \sim T^{1 / 2}$. For attracting Coulomb center at room temperature $S_{n} \sim T^{-2}$ [11]. Therefore:

$$
N_{c}(T) V_{T}(T) S_{n}(T) \simeq \operatorname{const}(T)
$$

If this relation is not absolutly exact, the temperature dependence of expression (15) will be much weaker than the exponential dependence. Consequently, for deep levels $\left(E_{t}>>k T\right)$ and small temperature changes the temperature dependence of $\left(N_{c} V_{T} S_{n}\right)$ can be neglected in equ. (3). Having two times $\tau_{1}$ and $\tau_{2}$ for two different temperatures $T_{1}$ and $T_{2}$, we can to calculate $E_{t}$ by equ. (16):

$$
E_{t}=\frac{k T_{2} \ln \left(\tau_{1}\left(T_{1}\right) / \tau_{2}\left(T_{2}\right)\right)}{\left(T_{2} / T_{1}\right)-1}
$$

One can enhance the precision of $E_{t}$ determination by using a plot of $\ln (\tau)$ on $T^{-1}$, if the experiments are done in some temperature range:

$$
\ln (\tau(T))=\left(E_{t} / k T\right)+\operatorname{const}(T)
$$

The curves of these dependences are direct lines. The angles of the declination of these plots are set by the value of $E_{t}$. Thus it is possible to define the value of $E_{t}$ for each trap level.

\section{SAMPLES AND EXPERIMENTAL TECHNIQUE}

We investigated three types of GaAs-samples. The first one labeled a GA-1 is the structures of the epi-layer $n$-GaAs on the $n$-GaAs substrate. They were achieved by an industrial vapor phase epitaxy method in the system $\mathrm{Ga}-\mathrm{AsCl}_{3}-\mathrm{H}_{2}$. The substrate, $0.35 \mathrm{~mm}$ thick, was doped by Te with $N_{\mathrm{Te}} \approx(1 \div 2) \times 10^{18} \mathrm{~cm}^{-3}$. The free carrier concentration of the epi-layers, doped by Te too, 6-9 microns thick for different samples, was $(0.6 \div 1.2) \times 10^{15}$ 
$\mathrm{cm}^{-3}$. The second one labeled as GA-2 consists of a $400 \mu \mathrm{m}$ thick GaAs-substrate with a $1 \mu \mathrm{m}$ thick epitaxial layer of $n$-GaAs on it. The third sample labeled as GA-3 consists of the GaAs substrate and a $8 \mu \mathrm{m}$ thick epitaxial layer with electron concentration $n \sim 10^{14} \mathrm{~cm}^{-3}$. GA-2 and GA-3 samples were fabricated by MOCVD process.
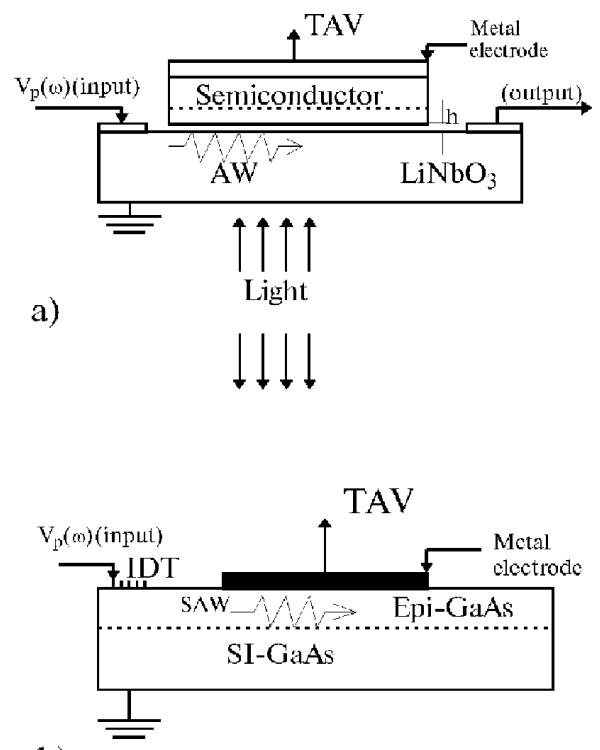

b)

Fig. 2. Two versions of sample arrangements performing transient TAV measurements: a) separate medium configuration, b) integrated configuration.

The samples GA-1 and GA-2 were placed by the epitaxial layer on the lithium niobate plate. On this plate SAW of $6 \mathrm{MHz}$ were excited. The TAV signal was picked up between a bottom ground electrode and a flat metal electrode attached on the upper surface of the GaAs sample as shown in fig. 2, a. This arrangement is very convenient because no special sample preparation is required and sample replacement is easy to do. For example, it is not necessary to form electrical contacts to the samples. As far as GaAs is a piezoelectric material, it can simultaneously play the role of the piezoelectric waveguide as shown in fig. 2, b (for GA-3). In this case SAW of $67 \mathrm{MHz}$ are excited by means of an interdigital transducer deposited on the sample surface. The TAV signal was measured between the ground electrode and the aluminum film which has to be evaporated on the epitaxial layer.

\section{EXPERIMENTAL RESULTS AND DISCUSSION}

\section{A. THE EXPERIMENTAL DEFINITION OF THE TRANSIENT TAV RELAXATION TIMES}

The task of the subsequent mathematical procedure consists in finding out the values of $V_{i}, \tau_{i}$ and $N$ from equ. 6. For this aim it is necessary to determine the number of effectively acting types of surface levels $N$. Therefore we have to analyze the plots $\ln \left(V_{a e}\right)$ versus time. For $N=1$ this dependence should be a straight line. Its slope gives the relaxation time $\tau$. In the case of two or more exponential components this plot has a more complex form. The number of rectilinear sites on these curve corresponds to the number of trap centers. One can define characteristic relaxation times from the declination angles of these directs. In our experiments the values $V_{i}$ and $\tau_{i}$ were estimated by the interpolation of the transient TAV signal (part "BC" in fig. 1) with the help of a special computer program which had found out the number of different type levels simultaneously. The data obtained from GA-2 show the occurrence of two exponential terms with the decay times of 2 and $12 \mathrm{~ms}$. In fig. 3 the parts "ab" and "bc" of the curve 1 correspond to two types of traps having the relaxation times 2 and $12 \mathrm{~ms}$, respectively. The experiments with the GA-3 sample show two different terms in total TAV signal corresponding to the two parts "ab" and "bc" of the curve 2 shown in fig. 3. We can distinguish two types of trapping centers having relaxation times of 4.5 and $22 \mathrm{~ms}$ at room temperature. Four local centers having relaxation times of $2.2,1,22$ and $1.7 \mathrm{~ms}$ were also found in the samples GA-1 at room temperature.

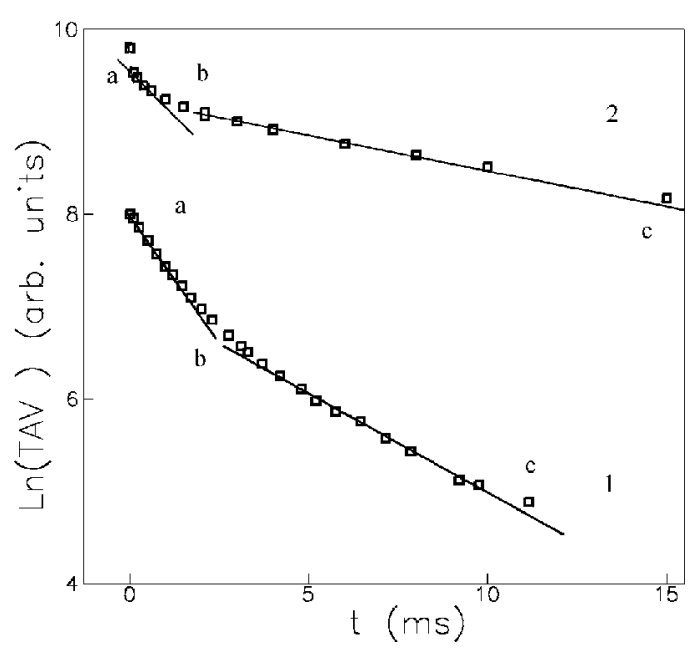

Fig. 3. Logarithmic plot of transient TAV signal versus time. 1 is plot for GA-2 and 2 is plot for GA-3. Parts "ab", and "bc" correspond to different types of trapping centers.

Additional measurements were carried out for a further identification of these trap centers and for the definitions of their parameters. The relaxation time of a transient TAV was measured at various temperatures in the GA-1 samples (see item 2.3). The samples GA-2 and GA-3 were used to measure spectral dependencies of a TAV signal (see item 2.2). 


\section{B. TEMPERATURE DEPENDENCES OF THE TRANSIENT TAV}

The descending parts of the TAV signal for the GA1 series at various temperatures are presented on fig. 4 . We can see, that the TAV relaxation time decreases with the temperature increase. Our measurements were carried out in the temperature range of 294 to $330 \mathrm{~K}$.

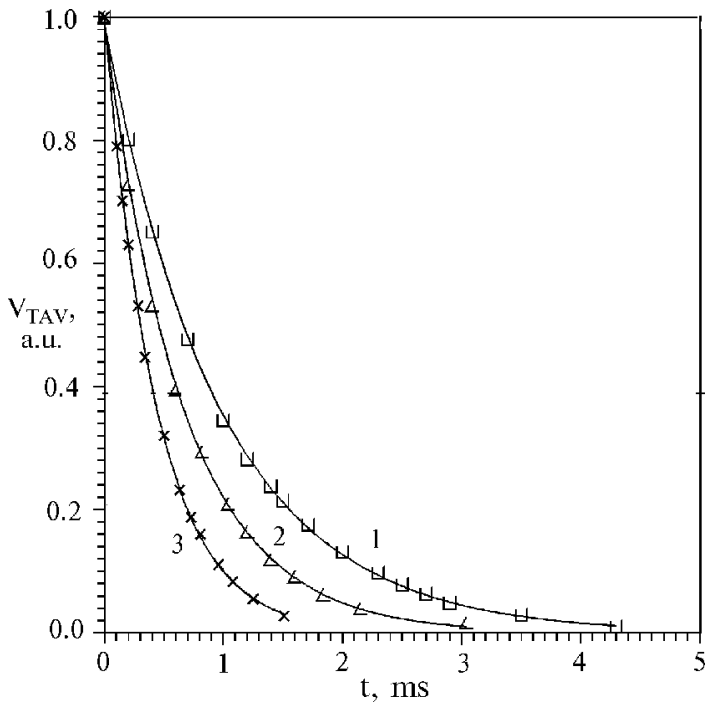

Fig. 4. Shape of the descending parts of the TAV signal at various temperatures for GA-1: $296 \mathrm{~K}(1), 305 \mathrm{~K}(2)$ and 318 K (3). Points - experimental data; curves - theoretical calculation by equ. (6).

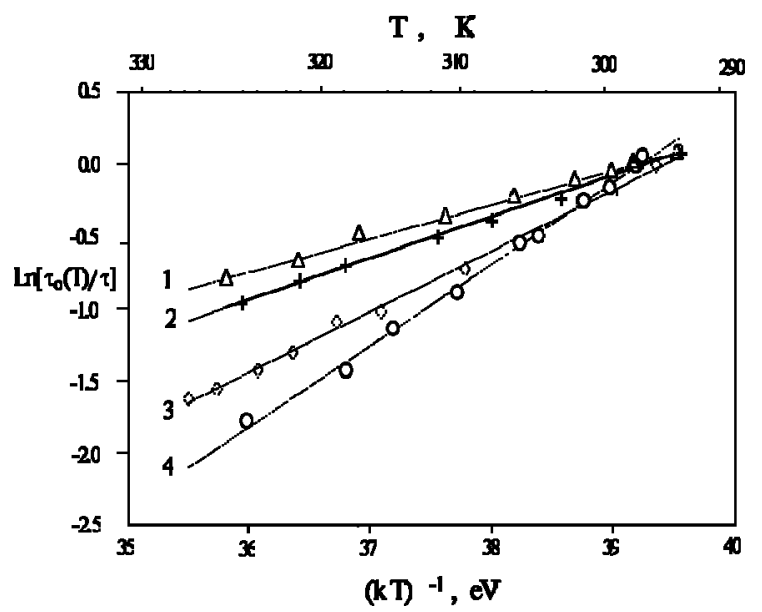

Fig. 5. Dependence of $\tau$ on $T^{-1}$ (GA-1). At room temperature the relaxation time $\tau$ is equal to $2.2 \mathrm{~ms}$ for the plot $1,1.0$ ms plot 2, $22 \mathrm{~ms}$ plot 3 and $1.7 \mathrm{~ms}$ plot 4 . The slops of plots $1,2,3$ and 4 give four levels $E_{1}, E_{2}, E_{3}, E_{4}$, respectively.
The plots of $\tau$ on $T^{-1}$ are shown on fig. 5. Practically they are direct lines, angles of declination of these lines give the trap level energy positions $E_{t}$. Knowing the characteristic relaxation times of the excess charge $\tau_{i}$ and the energy levels of the interface centers $E_{t i}$, we can calculate the effective capture cross section $S_{n i}$ for these levels by equ. (3).

Thus, four deep levels were detected at the samples under study. They were designated as levels $E_{1,2,3,4}$. The characteristic parameters of the said centers are presented in the tabl. 1 . The characteristics coincidence of the $E_{4}$ level and the data from literature [12] allows us to say that $E_{4}$ is electron center EL3. The configuration $\mathrm{As}_{i} V_{\mathrm{Ga}}$ is assigned with this level. Indeed, the excess of the interstitial arsenic $\left(\mathrm{As}_{i}\right)$ and the gallium vacancies $\left(V_{\mathrm{Ga}}\right)$ should be observed in the GaAs, doped by tellurium. Certainly, the tellurium interstitial $\left(\mathrm{Te}_{i}\right)$ can be significant at this case too. It is possible to conclude, that level $E_{1}$ is the EL17 center [13-15], $E_{3}$ being the EL5 center [14]. Level $E_{2}$ can be identified as the electron center EL6 [16]. All these levels deal with the vacancies of gallium $\left(V_{\mathrm{Ga}}\right)$ and arsenic $\left(V_{\mathrm{As}}\right)$ [13-16].

\begin{tabular}{|c|c|c|c|c|c|}
\hline Samples & Level & Type & $E_{t}, \mathrm{eV}$ & $\tau, \mathrm{ms}$ & $S_{n}, \mathrm{~cm}^{2}$ \\
\hline GA-1 & $E_{1}$ & EL17 & $0.23 \pm 0.02$ & $2.2 \pm 0.2$ & $0.7 \times 10^{-18}$ \\
\hline GA-3 & $E_{1}^{*}$ & EL17 & $0.20 \pm 0.01$ & $4.5 \pm 0.4$ & $1.5 \times 10^{-19}$ \\
\hline GA-1 & $E_{2}$ & EL6 & $0.29 \pm 0.02$ & $1.0 \pm 0.1$ & $1.6 \times 10^{-17}$ \\
\hline GA-1 & $E_{3}$ & EL5 & $0.42 \pm 0.02$ & $22 \pm 2$ & $1.4 \times 10^{-16}$ \\
\hline GA-1 & $E_{4}$ & EL3 & $0.56 \pm 0.02$ & $1.7 \pm 0.2$ & $4 \times 10^{-13}$ \\
\hline GA-2 & $E_{4}^{*}$ & EL3 & $0.54 \pm 0.01$ & $2 \pm 0.03$ & $2.5 \times 10^{-13}$ \\
\hline GA-3 & $E_{5}$ & EL4 & $0.48 \pm 0.01$ & $22 \pm 1$ & $2 \times 10^{-15}$ \\
\hline GA-2 & $E_{5}^{*}$ & EL4 & $0.48 \pm 0.01$ & $12 \pm 1$ & $4 \times 10^{-15}$ \\
\hline
\end{tabular}

Table 1. Characteristics of interface trapping centers in epiGaAs at room temperature.

\section{EXPERIMENTAL SPECTRA OF THE TRANSIENT TAV}

Also, for the determination of trapping level energy the optical spectra of transient TAV are investigated. A sample under investigation is illuminated with the monochromatic light in the range from 0.6 to $1.6 \mathrm{eV}$. Then TAV signal is separated for partial exponential components with different relaxation times $\tau_{i}$ with the help of a special computer program in general. Each such component is characterized by a certain value of partial amplitude $V_{i}$ which varies during illumination. The said amplitudes $V_{i}$ determines the contribution to a total TAV signal of $i$-type traps having relaxation time $\tau_{i}$. This contribution reaches the minimum at the illumination of sample surface by monochromatic light with the photon energy equal $E_{G}-E_{t i}$, in accordance with formula (13). Thus a spectral position of the minimum in a spectrum of the $i$-partial amplitude $V_{i}(h \nu)$ determines the appropriate energetic level $E_{t i}$. 
The spectra of partial amplitudes $V_{i}$ are shown on fig. 6 . The plots (1 and 2 ) are taken from the GA-2 sample for the relaxation times 12 and $2 \mathrm{~ms}$, respectively. The minima on these curves correspond to the two types of deep levels at $E_{5}^{*}=0.48 \mathrm{eV}$ and $E_{4}^{*}=0.54 \mathrm{eV}$ below the conduction zone. The plots 3 and 4 are taken from GA-3 sample for the relaxation times $22 \mathrm{~ms}$ and $4.5 \mathrm{~ms}$, respectively. The minima on plots 3 and 4 correspond to two types of deep levels at $E_{5}=0.48 \mathrm{eV}$ and $E_{1}^{*}=0.20 \mathrm{eV}$ below the conduction zone.

Now, knowing the energy positions of trapping centers and the related relaxation times, we can calculate the effective cross sections $S_{n}$ for the capture of charge carriers by these trap centers. Below, characteristic defect parameters in the epitaxial GaAs structures under study are presented in the Table. The defect identification was done by comparing the energetic position with the literature data on deep levels in GaAs [12,13, 17-20]. One can see, that deep trap levels of the types EL3 and EL17 are detected both with the help of spectral research and measurements of the TAV relaxation times' temperature dependencies.

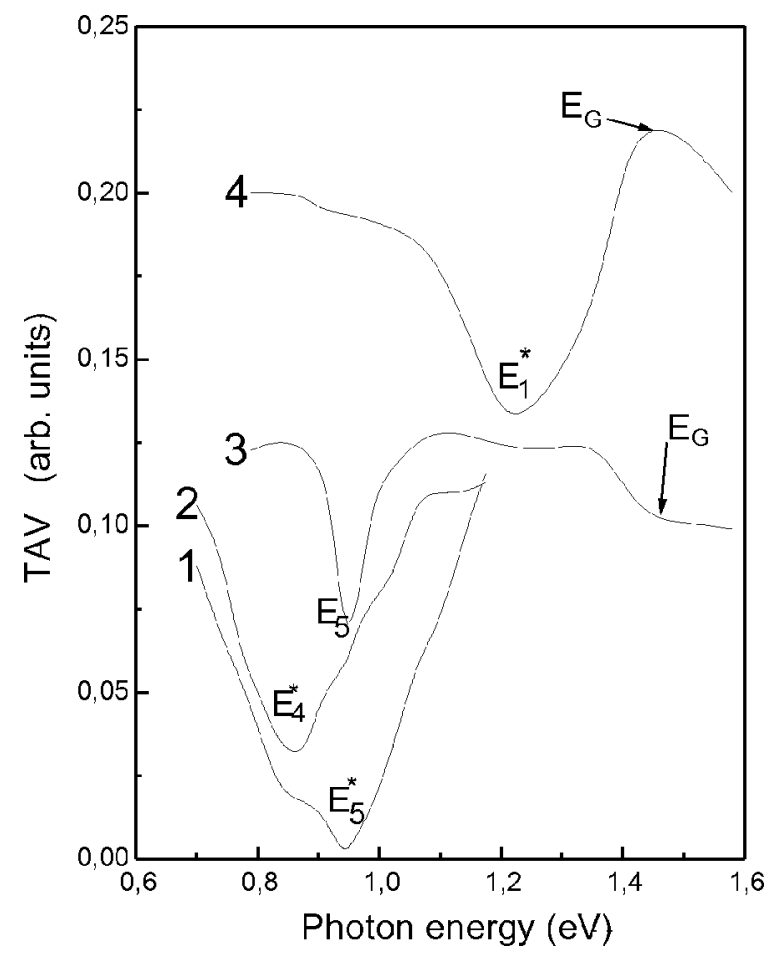

Fig. 6. Spectra of the TAV exponential component. 1 $\tau=12 \mathrm{~ms}(\mathrm{GA}-1) ; 2-\tau=2 \mathrm{~ms}(\mathrm{GA}-2) ; 3-\tau=22 \mathrm{~ms}$ (GA-3); $4-\tau=4.5 \mathrm{~ms}$ (GA-2). The four minima labeled as $E_{1}^{*}, E_{4}^{*}, E_{5}, E_{5}^{*}$ correspond to the three trapping centers detected in the samples under study. The band gap energy is marked by $E_{G}$.
The difference in values of relaxation times for the levels $E_{1}, E_{1}^{*}$ and $E_{5}, E_{5}^{*}$ in different samples can be explained as follow. The relaxation time of the captured charge is determined by two parameters - the energy depth $E_{t}$ of the trapping center and its capture crosssection $S_{n}$. The said $E_{t}$ depends on the atomic structure of the local defect and so does not vary from sample to sample. Conversely, the value $S_{n}$ depends both on the type of trapping level and on the electrical properties of the semiconductor itself, including the configuration of electrical potential near the defect and its shielding by a free charge. Therefore the characteristic relaxation times for the same trapping levels, but varying on the manufacturing samples, can differ from each other.

\section{CONCLUSIONS}

The acousto-electric method can be advantageously applied for studying interfaces in modern epilayer semiconductor structures. The experimental data followed by the appropriate mathematical processing allow to estimate the characteristic relaxation time, energy position in the forbidden zone and the electron capture crosssection for each of these centers. By this approach we, for the first time, measured the relaxation times of trap centers.

Investigating the interface between the epitaxial GaAs-layers grown on the substrate by the MOCVD process and the chlorine vapor method we found five different types of trapping defects. They were identified as EL3, EL4, EL5, EL6 and EL17 centers. Their characteristics at room temperature are summarized in the Table.

The different GaAs centers are known to be observed in the samples, achieved by a different technique [13]. The coincidence of the level's parameters permit to conclude that levels EL5 and EL17 can be present in the epitaxial structures reached by the chlorine vapor method as well as by the MOCVD technique.

The method described can also be applied to the investigation of other semiconductor structures, including those based on the Si and $A_{2} B_{6}$ compounds.

Summarizing the obtained results we may conclude that the transient TAV technique is a reasonably simple and effective method for characterizing surface and interface trap centers.

\section{ACKNOWLEDGMENTS}

We kindly acknowledge the Bundesministerium für Bildung, Wissenschaft, Forschung und Technologie, Deutschland, and the ISSEP Program of International Soros Foundation for partial financial supporting of the project. 
[1] V. A. Jurjev, V. P. Kalinushkin and O. V. Astafjev, Fiz. Tekhn. Poluprovodn. 29, 455 (1995).

[2] A. S. Popov and A. Y. Bahnev, Phys. Status Solidi A, 122, 569 (1990).

[3] Yu. D. Tkachev, V. S. Lysenko and V. I. Turchanikov, Phys. Status Solidi A, 140, 163 (1993).

[4] A. Abbate, K. Han, I. Ostrovskii and P. Das, Solid-State Electron. 36, 697 (1993).

[5] I. V. Ostrovskii, A. Abbate, K. J. Han and P. Das, IEEE Transact. Ultrason., Ferroelect., Freq. Control 42, 876 (1995).

[6] I. V. Ostrovskii and S. V. Saiko, Fiz. Tekhn. Poluprovodn. 28, 796 (1994).

[7] M. Tabib-Azar, Nam-Chun Park and P. Das, Solid-State Electron. 30, 705 (1987).

[8] V. A. Vyun, V. V. Pnev and I. B. Yakovkin, in Proceedings of the Int. Symp. Surface Waves in Solids and Layered Structures (Novosibirsk, 1986) 2, p. 354.

[9] Ju. V. Guljaev, A. M. Kmita, A. V. Medved, V. P. Plesskii, N. N. Shybanova and V. N. Fedorez, Fiz.
Tverd. Tela 17, 3505 (1975).

[10] A. Ricksand and O. Engstrom. J. Appl. Phys. 70, 6915 (1991).

[11] V. N. Abakumov, I. N. Yassievitch, Zh. Eksp. Teor. Fiz. 71, 657 (1976).

[12] M. M. Sobolev et al., Semiconductors 30, 1108 (1996).

[13] G. M. Martin, A. Mitoneau, A. Mircea, Electron. Lett. 13, 172 (1977).

[14] V. A. Samojlov, N. Ja. Jakhusheva, V. Ja. Princ, Semiconductors 28, 1617 (1994).

[15] R. A. Morrou. J. Appl. Phys., 69, 3396 (1991).

[16] Zh.-O. Fang, Schlesinger, J. Appl. Phys. 61, 5047 (1987).

[17] D. Goguenheim, D. Viullaume, G. Vincent and M. Noble, J. Appl. Phys. 68, 1104 (1990).

[18] E. A. Bobrova, G. N. Calkin, V. L. Oplesnin, M. G. Tigishvili, Povierkhnost' 3, 130 (1991).

[19] A. P. Kasatkin, V. A. Perevoshchikov, V. D. Skupov, L. A. Suslov, Povierkhnost' 6, 79 (1993).

[20] B. I. Siosoev, N. K. Bezredin, G. I. Kotov, Fiz. Tekhn. Polupr. 29, 24 (1995).

\title{
АКУСТОЕЛЕКТРИЧНЕ ДОСЛІДЖЕННЯ РІВНІВ ЗАХОПЛЕННЯ НА ІНТЕРФЕЙСІ ЕПІТАКСІЯЛЬНИХ СТРУКТУР GaAs
}

\author{
I. В. Островський ${ }^{\dagger}$, С. В. Сайко, О. Я. Оліх ${ }^{\dagger}$, Г. Г. Вальтер \\ ${ }^{\dagger}$ Київсъкий університет імені Тараса Шевченка, фізичний факультет, \\ Київ, UA-252022, Украӥна \\ ${ }_{\ddagger}^{\ddagger}$ Університет Фрідріха Шиллера, Інститут оптики та квантової електроніки, \\ 07743, Сна, Німеччина
}

\begin{abstract}
Робота присвячена методові акустоелектричної релаксаційної спектроскопії глибоких рівнів. Поряд 3 теоретичним аналізом наведено результати його практичного застосування. Цей метод грунтується на вивченні спектральної та температурної залежностей поперечної акустоелектричної напруги, що виникає в п'єзонапівпровідниках при поширенні акустичної хвилі. Він дає змогу досліджувати глибокі рівні в забороненій зоні напівпровідників, що розташовані як безпосередньо на іхній поверхні, так і на межі поділу епішар-підкладка в епітаксіяльних структурах. Зокрема, можливим є визначення характерного часу релаксації заряду на цих рівнях, іхньої енергетичної глибини залягання та площі поперечного перерізу захоплення носіїв. У роботі подано результати досліджень ряду епітаксіяльних структур на базі арсеніду галію, виготовлених за допомогою MOCVD технології та методу газофазової епітаксії. У цих структурах виявлено п'ять рівнів: EL3, EL4, EL5, EL6 і EL17 та визначено іхні параметри.
\end{abstract}

